\title{
Effect of Flower Farm Effluents on Diversity and Composition of Macro Invertebrates in Marura Wetland
}

\author{
Daniel Albert Wandera, Monicah Nanjala Mukhwana \\ Department of Fisheries and Aquatic Science, University of Eldoret, Eldoret, Kenya
}

Email address:

dawandera@gmail.com (D. A. Wandera),m.mukhwana91@gmail.com (M. N. Mukhwana)

To cite this article:

Daniel Albert Wandera, Monicah Nanjala Mukhwana. Effect of Flower Farm Effluents on Diversity and Composition of Macro Invertebrates in Marura Wetland. Agriculture, Forestry and Fisheries. Vol. 5, No. 6, 2016, pp. 207-214. doi: 10.11648/j.aff.20160506.11

Received: August 28, 2016; Accepted: September 12, 2016; Published: October 9, 2016

\begin{abstract}
Wetlands are important sites for biological conservation due to their rich biodiversity which possess high productivity. They also offer shelter to many organisms and offers services such as water purification and flood control. However, biodiversity in wetlands has been reduced due to human activities that cause pollution like, flower farm effluents which are discharged directly to wetlands or river systems. Four water quality parameters; DO, BOD, pH, TDS, TSS and macro-invertebrates composition were investigated at four different stations (S1, S2, S3, S4) adjacent to Equator Flower Farm along the Marura wetland. PAST program was used to calculate diversity indices and richness in the macroinvertebrates communities. Station S2 had the highest temperature $\left(22.6^{\circ} \mathrm{C}\right)$, whereas $\mathrm{S} 4$ had the lowest temperature $\left(19.6^{\circ} \mathrm{C}\right)$. The $\mathrm{pH}$ value did not vary along the stations (8.3-6.3). The DO level fluctuated along the river, station S1 had highest level of $3.6 \mathrm{~m} / 1$ and lowest station S3 had $0.8 \mathrm{mg} / \mathrm{l}$. TSS and TDS did not show significant variations, while BOD levels varied with different stations. The highest value of TN was recorded at Station $3\left(0.33 \pm 0.045 \mathrm{mgl}^{-1}\right)$. There was no significant difference $(\mathrm{p}=0.055)$ in three stations (S1, S2, S4) except S3. In total 10 orders, 30 genera and 30 families of macroinvertebrates were identified. The orders; Odonata, Coleoptera, Hemiptera and Diptera were the main macroinvertebrates found in all station, while the members of orders; Ephemeroptera, Trichoptera, Oligochaeta Mollusca, Gnathobellidae and Isopoda were few in all sampling stations. Station S2 and S4 had the highest species diversity compared to station S1 and S3 which had the lowest diversity. DO, BOD and temperature were found to have a significant effect on abundance and composition of benthic organisms with S3 having less abundance due to its proximity to the flower farm.
\end{abstract}

Keywords: Bioindicators, Benthic Macroinvertebrate, Wetlands, Water Quality

\section{Introduction}

Wetlands, which covers about $2 \%$ of the land surface, are important sites for biological conservation because they support a rich biodiversity (Mitsch and Gosselink, 2000). The ecological significance of wetlands is widely acknowledged globally. They are known to provide habitat to large number of aquatic organisms, offer ecosystem services such as water purification, nutrient cycling, carbon sequestration and also flood control. Some are used as source of medicinal plants and cultural practices by the communities residing near the wetlands (Macharia et al., 2010). The rapid increase of human population growth around the globe, has led to high demand for; basic, economical and settlement needs. Many communities, mostly in developing countries depend heavily on exploitation of the natural resources for their livelihood.
The exploitation may be on small scale level like fishing, irrigation and herbal plants services or on a large scale such as water purification plants and commercial flower farms. These varied uses of natural resources together with an enormous increase in the amount of waste produced, are placing demands on aquatic ecosystems and thus, streams and rivers continue to bear the consequences of pollution (Masese et al., 2009). This trend, coupled with freshwater scarcity in most countries, (Postel 1992), continues to strain available aquatic resources. As a result, these delicate ecosystems have increasingly lost their integrity, leading to sedimentation and eutrophication of the receiving water bodies such as rivers, reservoirs and wetlands (GEF, 2004).

Macro-invertebrates are organisms that lack a backbone. 
Some undergo incomplete metamorphosis while others undergo complete metamorphosis in their life cycle (Wetzel, 1979). These macro-invertebrates are found in both terrestrial and aquatic environments (Clenaghan et al., 1998). They are large enough to be seen by the naked eyes and play a big role in the aquatic food webs (Wetzel, 1979). They are also operationally defined as those invertebrate animals which will not pass through a $0.5 \mathrm{~mm}$ sieve (Winterbourn, 2000). The most well-known and diverse of the stream taxa are the insects which include the mayflies (Ephemeroptera), stoneflies (Plecoptera), and caddis flies (Trichoptera), collectively known as the EPT taxa, but also the Dipterans or true flies. Other examples of macro-invertebrates include flatworms, crayfish, snails and clams. Macroinvertebrates are used as bioindicators of pollutants in the aquatic ecosystem for several reasons (Chapman, 1996): They show effects of short term environmental variations because most of them have a sensitive life stages and will make them respond quickly to stress.

The heavy use of fertilizer and pesticides in the flower farms pose great risk to the nearby water bodies and especially the wetlands. Most of this effluents such as waste water originating from the flower farms are directly discharged into the wetlands. The use of fertilizers may cause large concentration of nutrients such as phosphates and nitrogen to accumulate in water bodies. This poses a threat to resident macroinvertebrates and the water quality. The study was designed to investigate the effects of flower farm wastewater effluents in Marura wetland ecosystem diversity and chemo-physical parameters. The composition and distribution of benthic macro-invertebrates was also analysed alongside the water quality parameters; temperature, dissolved oxygen, (DO) biological oxygen demand (BOD), $\mathrm{pH}$, total dissolved solids (TDS) and total suspended solids (TSS).

\section{Materials and Methods}

\subsection{Study Area}

The study was carried out in Marura wetland, which is located near the University of Eldoret and about $7 \mathrm{Km}$ from Eldoret town. Has catchment area of about $210 \mathrm{Km}^{2}$ (Jaetzold and Schmidt, 1983).

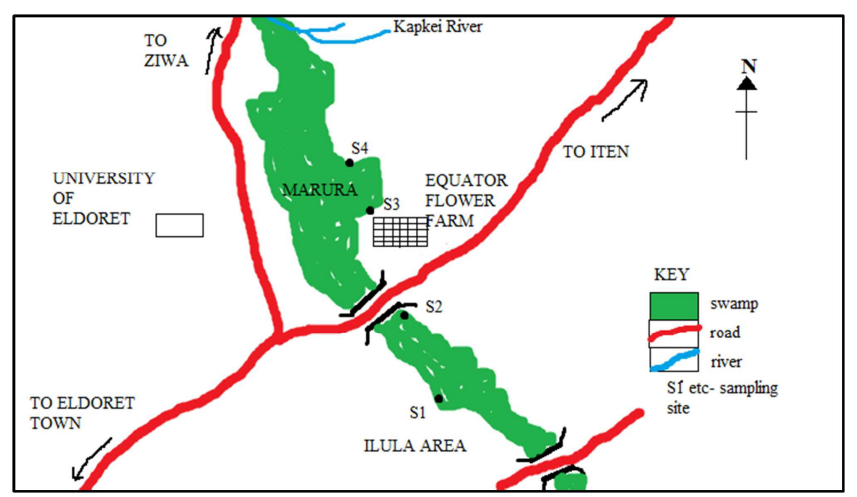

Figure 1. Sketch map of the study area.

\subsection{Sampling}

Samples were collected in all four sites. Water samples, in triplicates, were collected once every two weeks from November 2014 to march 2015. The water samples at point of collection, were measured for various parameters such as $\mathrm{pH}$ and temperature and preserved for nutrients analysis; phosphates, nitrogen and ammonia. Samples for water quality were collected before the sampling of the benthic organisms to avoid contamination due to water disturbance during benthos sampling. Macro-invertebrates samples were also collected once every two weeks in triplicates, during the period of study. The triplicate samples $(250 \mathrm{ml})$ for dissolved oxygen (DO), were fixed insitu before determination.

\subsection{Nutrients}

Triplicates samples for nutrients (nitrogen, phosphates) and ammonia were collected and analysed according to APHA (2005).

\subsection{Macro-invertebrates}

Benthic macro-invertebrates were collected using a dip net and placed in plastic containers after being washed by water through $300 \mu \mathrm{m}$ sieve and sorted while still alive. They were then fixed with $4 \%$ formalin and taken to the laboratory for identification using benthic macro-invertebrate keys by Gill (2008) and a Gerber and Gabriel (2002), counted, recorded and classified into various genera. The macro invertebrates diversity were determined for each sampling station using number of taxa, total number of individual and relative abundance which was calculated as the proportion of each taxa in a station. The relative abundance was calculated as:

$$
\text { R. A }=\frac{\text { No.of individuals of one taxon } * 100}{\text { Total no.of individuals in a station }}
$$

The Simpson Index (Ds) was used as a measure of taxon richness. The index is given by:

$$
D s=\sum_{i=j}^{i=n} \frac{\left[\sum n_{i}\left(n_{i}-1\right)\right]}{[N(N-1)]}
$$

Where; $\mathrm{ni}$ is the number of species in the sample and, $\mathrm{N}$ is the total number of individuals in each station counted and classified into various genera.

\subsection{Data Analysis}

Analysis was done using Minitab version 14 (Minitab, State College, PA) Excel (Microsoft Inc.) and Paleontological Statistics (PAST) software package (Version 2.17; Hammer et al. 2001). One-way analysis of variance (ANOVA) was used to test for differences between stations for water quality parameters and macroinvertebrates distribution and abundance at 95\% confidence levels. PAST program was used to calculate diversity indices and richness in the macro-invertebrates 
communities where by; Total taxa $(\mathrm{S})$, total individuals $(\mathrm{N})$, Dominance index (D), Evenness index (J') Simpson diversity index (Ds) and Shannon-Wiener index $\left(\mathrm{H}^{\prime}\right)$ were determined.

\section{Results}

The mean temperature was $21.08 \pm 0.035^{\circ} \mathrm{C}$ ranging from $22.6^{\circ} \mathrm{C}$ (S2) $-19.6^{\circ} \mathrm{C}$ (S4). There was no significant difference $(p<0.05)$ among the stations, with a mean of $7.025 \pm 0.2$. S3 (8.2) had the highest $\mathrm{pH}$ compared to other stations while S2 (6.3) had the lowest.

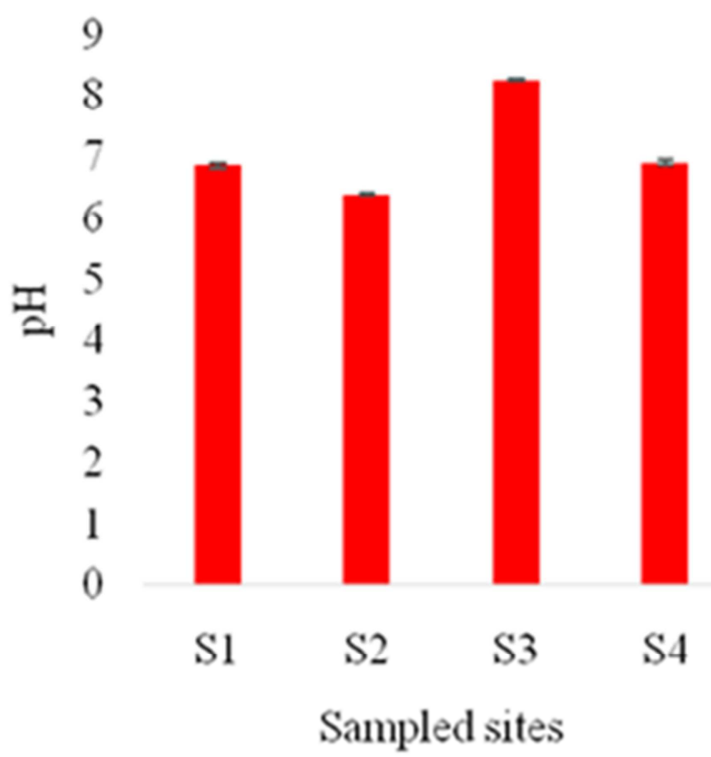

Figure 2. Graphs of mean temperature (left) and mean pH (right).

\subsection{Dissolved Oxygen}

Dissolved oxygen level at station S3 was lowest throughout the study period with a mean of $0.7 \pm 0.1 \mathrm{mgl}^{-1}$ while station $\mathrm{S} 1$ had the highest DO with a mean of $3.8 \pm 0.12 \mathrm{mgl}^{-1}$. The BOD level ranged from highest mean of $2.6 \pm 0.013 \mathrm{mgl}^{-1}(\mathrm{~S} 1)-$ $0.7 \pm 0.011 \mathrm{mgl}^{-1}$ at $\mathrm{S} 3$. The station $\mathrm{S} 3$ had the lowest DO and BOD.

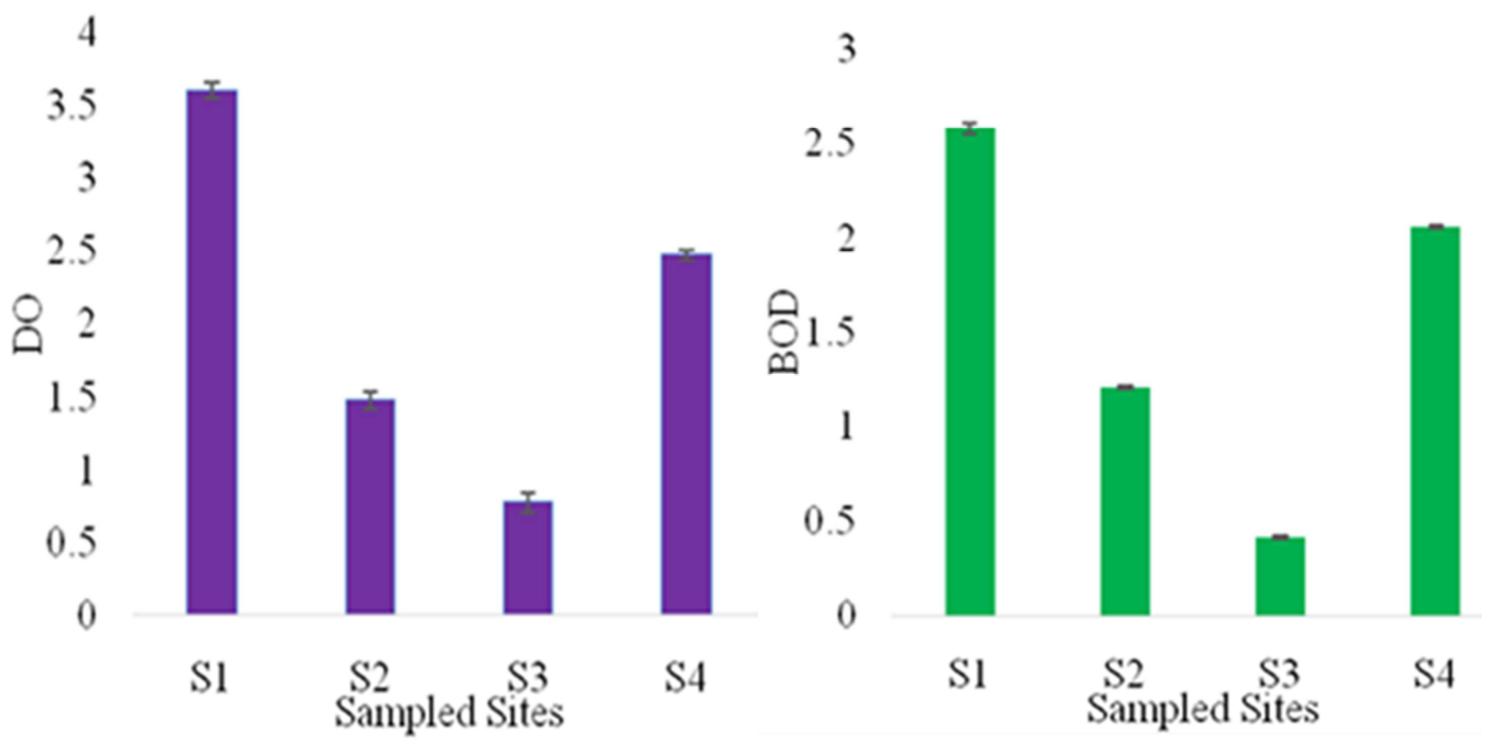

Figure 3. Graphs of Dissolved Oxygen (DO) (left) and Biological Oxygen Demand (BOD) (right) levels at the sampled sites.

\subsection{Total Dissolved Solids (TDS) and Total Suspended Solids (TSS)}

TDS values varied among all station recording a mean of $0.64 \pm 0.021 \mathrm{mgl}^{-1}$. Station 1 had the lowest TDS $(0.45 \pm 0.01 \mathrm{mgl})^{-1}$. The TSS ranged from $0.53 \pm 0.017 \mathrm{mgl}^{-1}$ at S3 to $0.22 \pm 0.02 \mathrm{mgl}^{-1}$ at S4. S3 was also found to have highest values of both TSS 
and TDS throughout the study.

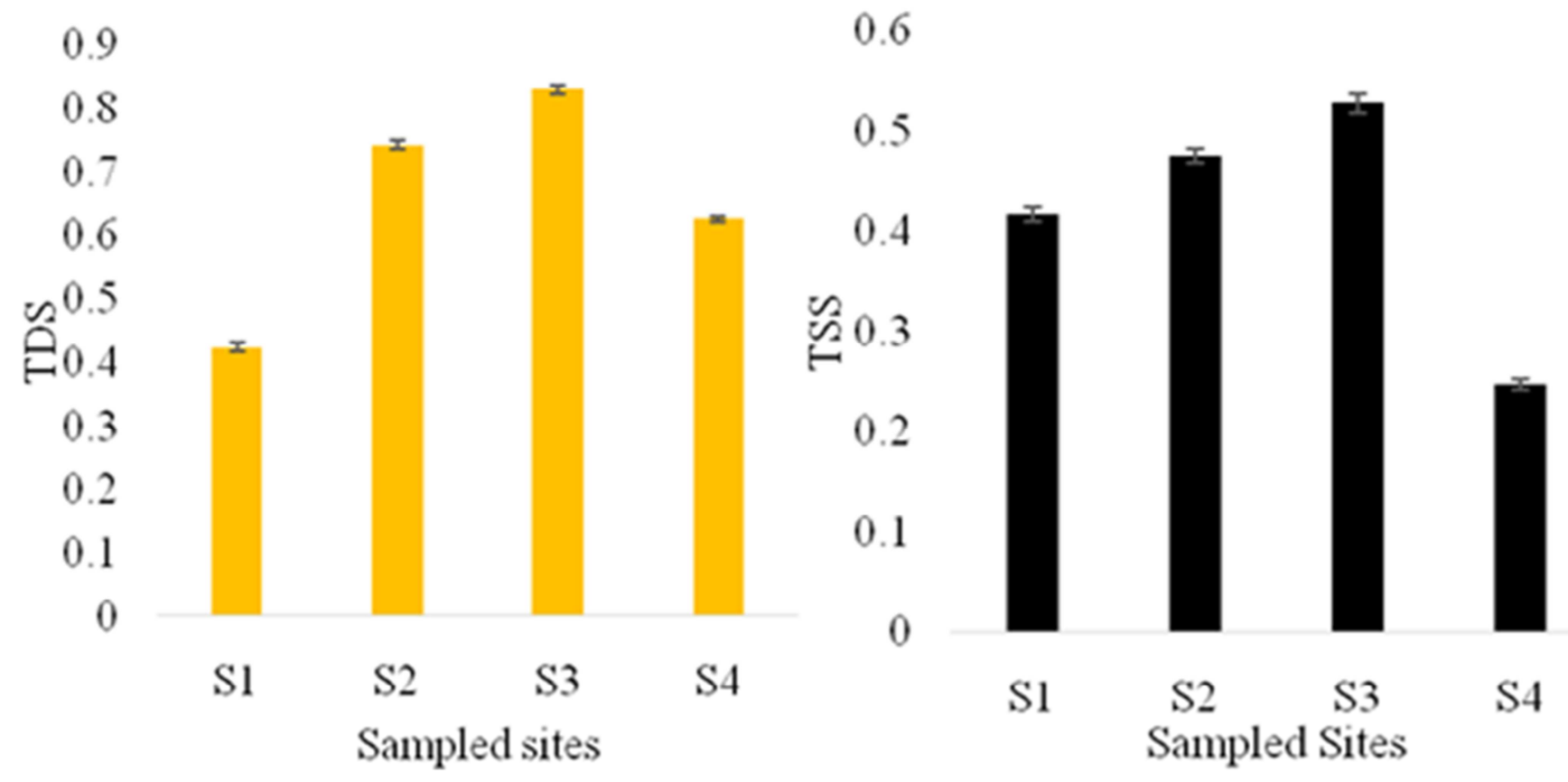

Figure 4. Graphs showing Total Dissolved Solids (TDS) (left) and Total Suspended Solids (TSS) (right) at the sampled sites.

\subsection{Nutrients}

\subsubsection{Total Nitrogen (TN) and Phosphate (TP)}

The highest value of TN was recorded at Station $3\left(0.33 \pm 0.045 \mathrm{mgl}^{-1}\right)$. There was no significant difference $(\mathrm{p}=0.055)$ in three stations (S1, S2, S4) except S3. The TP values followed the same trend as TN as the values for S3 were highest compared to the other 3 stations.
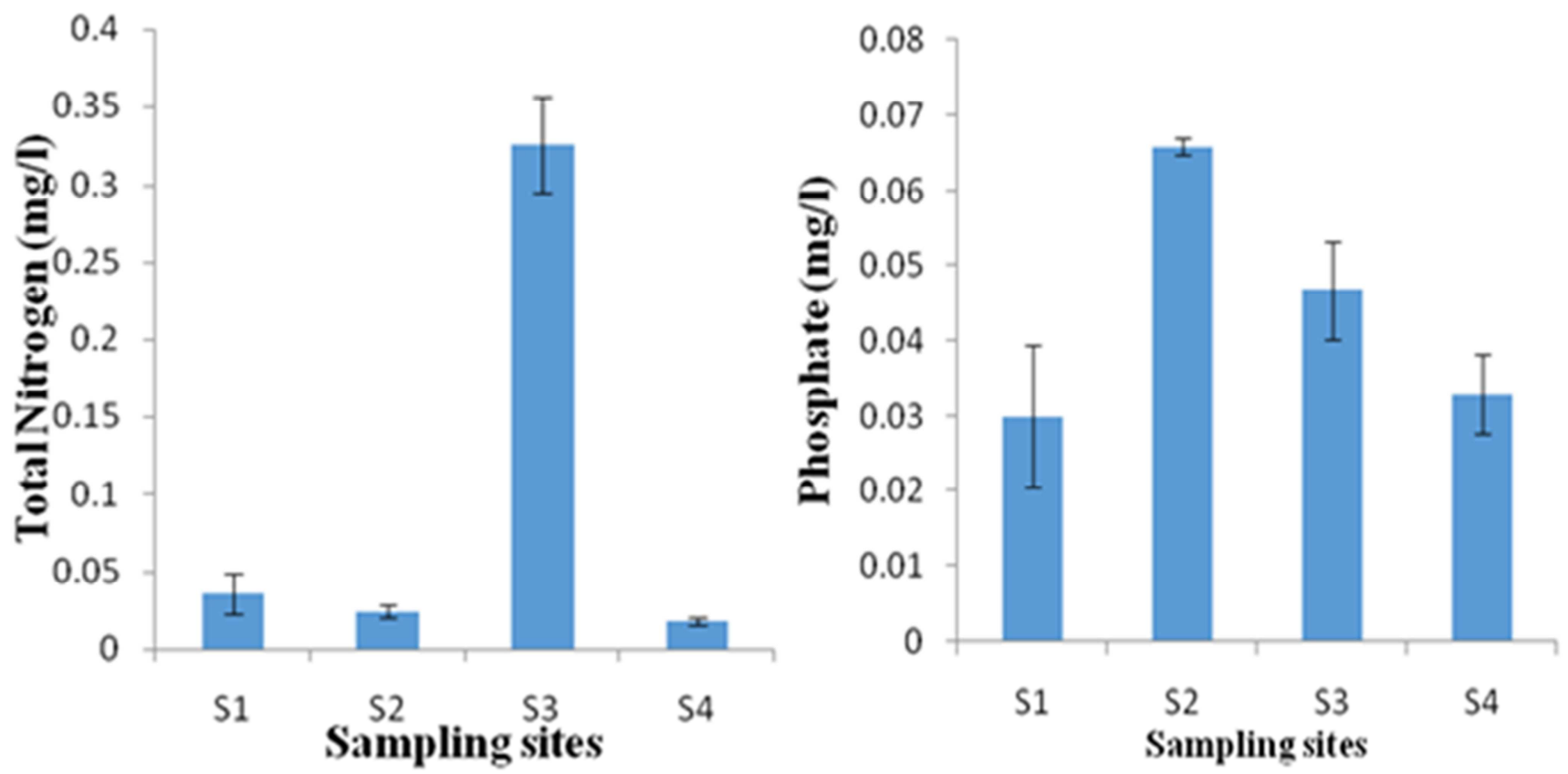

Figure 5. Total Nitrogen (left) and Phosphate (right) levels at the sampled sites.

\subsubsection{Ammonia}

The Ammonia levels varied significantly $(\mathrm{p}<0.05)$ among all the stations. S3 had the highest mean value of $0.435 \pm 0.0675 \mathrm{mgl}^{-1}$, while station S1 had the lowest ammonia value of $0.011 \pm 0.0012 \mathrm{mgl}^{-1}$. 


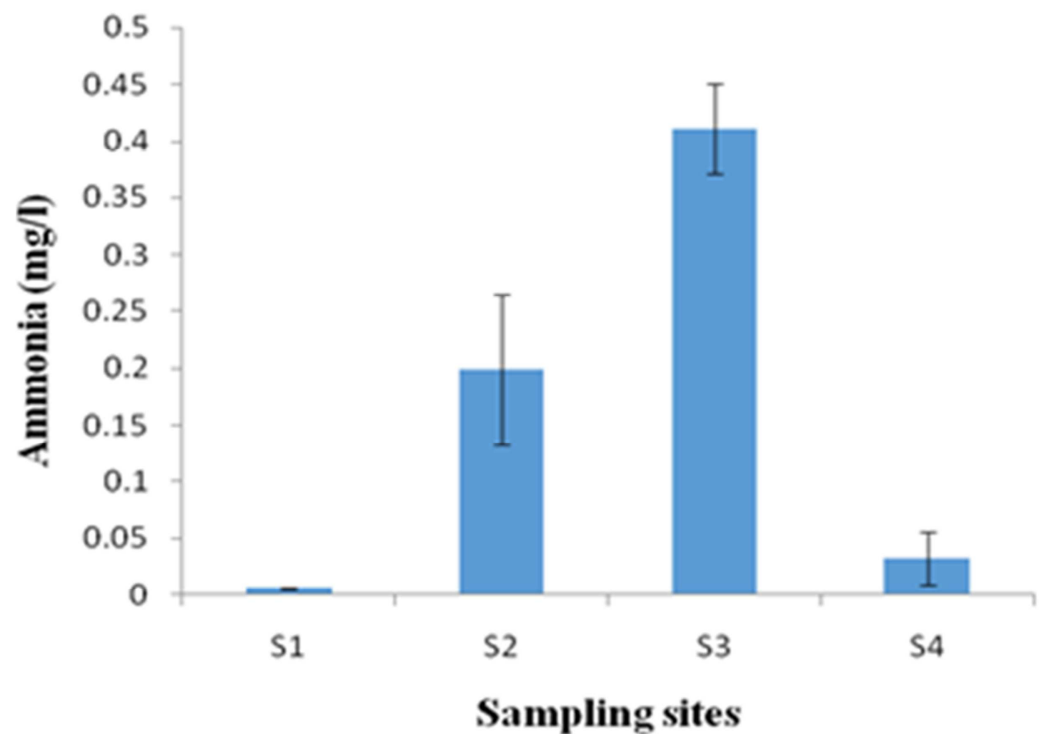

Figure 6. A graph showing the levels of Ammonia at the sampled sites.

\subsection{Benthic Macroinvertebrates}

There were 10 orders, 30 genera and 30 families identified in this study. Chironomus sp was the most common taxon that was found in all sampling stations. Syrphus sp. were least common as they appeared in one sampling site (Site 3). From the sampled sites, S1 (Site 1) had the highest number of families ie. it had 25 families whereas S3 (Site 3) had the lowest number of families with 14 in number.

Table 1. Occurrence and distribution of macroinvertebrate taxa and functional feeding groups in Marura Wetland: X indicates presence of taxa while empty spaces indicate their absence.

\begin{tabular}{|c|c|c|c|c|c|c|c|}
\hline \multirow{2}{*}{ Order } & \multirow{2}{*}{ Family } & \multirow{2}{*}{ Genera } & \multirow{2}{*}{ Functional Feeding Groups } & \multicolumn{4}{|c|}{ Sampling Sites } \\
\hline & & & & S1 & S2 & S3 & S4 \\
\hline \multirow{2}{*}{ Ephemeroptera } & Baetidae & Baetis spp. & Grazers & $\mathrm{X}$ & $\mathrm{X}$ & $\mathrm{X}$ & $\mathrm{X}$ \\
\hline & Caenidae & Caenis sp. & Gathering collector & $\mathrm{X}$ & & $\mathrm{X}$ & $\mathrm{X}$ \\
\hline \multirow[t]{3}{*}{ Trichoptera } & Ecnomidae & Ecnomina sp. & Filter feeders & $\mathrm{X}$ & $\mathrm{X}$ & & $\mathrm{X}$ \\
\hline & Culicidae & Culicida sp. & Filter feeders & $\mathrm{X}$ & & & \\
\hline & Chironomidae & Chironomus sp. & Filter feeders & $\mathrm{X}$ & $\mathrm{X}$ & $\mathrm{X}$ & $\mathrm{X}$ \\
\hline \multirow{4}{*}{ Diptera } & Simulidae & Simulium sp. & Filter feeders & & $\mathrm{X}$ & & \\
\hline & Ceratopogonidae & Ceratopogonium sp. & Filter feeders & & & & \\
\hline & Lumbricuridae & Lumbricus sp. & Gathering & & $\mathrm{X}$ & $\mathrm{X}$ & $\mathrm{X}$ \\
\hline & Syrphidae & Syrphus sp. & collector & $\mathrm{X}$ & & $\mathrm{X}$ & \\
\hline \multirow{7}{*}{ Hemiptera } & Hydrometridae & Hydrometra sp. & Predators & $\mathrm{X}$ & & $\mathrm{X}$ & \\
\hline & Gerridae & Gerris sp. & Predators & $\mathrm{X}$ & $\mathrm{X}$ & $\mathrm{X}$ & $\mathrm{X}$ \\
\hline & Veliidae & Vellia sp. & Predators & $\mathrm{X}$ & $\mathrm{X}$ & & $\mathrm{X}$ \\
\hline & Notonectidae & Notonecta sp. & Predators & $\mathrm{X}$ & $\mathrm{X}$ & & $\mathrm{X}$ \\
\hline & Belostomatidae & Belostome sp. & Predators & $\mathrm{X}$ & $\mathrm{X}$ & $\mathrm{X}$ & \\
\hline & Corixidae & Corixa sp. & Grazers & $\mathrm{X}$ & $\mathrm{X}$ & & $\mathrm{X}$ \\
\hline & Nepidae & Nepis sp. & Predators & & & $\mathrm{X}$ & \\
\hline \multirow[t]{3}{*}{ Oligochaeta } & Tubificidae & Tubifex sp. & Gathering collector & $\mathrm{X}$ & $\mathrm{X}$ & & $\mathrm{X}$ \\
\hline & Lestidae & & Predators & $\mathrm{X}$ & & & $\mathrm{X}$ \\
\hline & Zygoptera & & Predators & $\mathrm{X}$ & $\mathrm{X}$ & $\mathrm{X}$ & $\mathrm{X}$ \\
\hline \multirow[t]{3}{*}{ Odonata } & Libellulidae & Libellulium $\mathrm{sp}$. & Predators & $\mathrm{X}$ & $\mathrm{X}$ & & \\
\hline & Coenagrionidae & Coenagrionum sp. & Predators & $\mathrm{X}$ & $\mathrm{X}$ & & $\mathrm{X}$ \\
\hline & Gomphidae & Gomphus sp. & Predators & $\mathrm{X}$ & $\mathrm{X}$ & & $\mathrm{X}$ \\
\hline \multirow[t]{2}{*}{ Isopoda } & Gammaridae & Gammarus sp. & Gathering collector & $\mathrm{X}$ & & & $\mathrm{X}$ \\
\hline & Neucoridae & Neucoris sp. & Predators & $\mathrm{X}$ & & $\mathrm{X}$ & $\mathrm{X}$ \\
\hline \multirow{3}{*}{ Coleoptera } & Gyrinidae & Gerris sp. & Predators & $\mathrm{X}$ & $\mathrm{X}$ & & \\
\hline & Elmidae & Elmis sp. & Predators & $\mathrm{X}$ & & & \\
\hline & Dytiscidae & Daetis sp. & Predators & $\mathrm{X}$ & $\mathrm{X}$ & & \\
\hline
\end{tabular}


For diversity indices (eq 2.) S3 had highest dominance whereas S4 had the least dominance (Table 2). Macro-invertebrates in S4 were evenly distributed as compared to S1 and S3. In terms of relative abundance (Figure 7), S1 had the highest abundance whereas S3 had the least abundance. Diptera was most the abundant order in the sampled sites and was found in all sites whereas Mollusca was the least abundant as it was found in site one.

Table 2. Diversity indices of benthic macroinvertebrates at the four sampling stations during the study period of November $2014-F e b r u a r y 2015$.

\begin{tabular}{lllll}
\hline \multirow{2}{*}{ Diversity Indices } & Sampled Sites & & S3 \\
\cline { 2 - 4 } & S1 & S2 & 14 \\
\hline Taxa_S & 25 & 20 & 190 \\
No. of Individuals & 760 & 514 & 0.1396 \\
Dominance_D & 0.1194 & 0.0959 & 0.8604 & 287 \\
Simpson_1-D & 0.8806 & 0.9041 & 2.1991 \\
Shannon_H & 2.6010 & 2.6000 & 0.0936 & 0.9064 \\
Evenness_e^H/S & 0.5388 & 0.6729 & 2.5490 \\
\hline
\end{tabular}

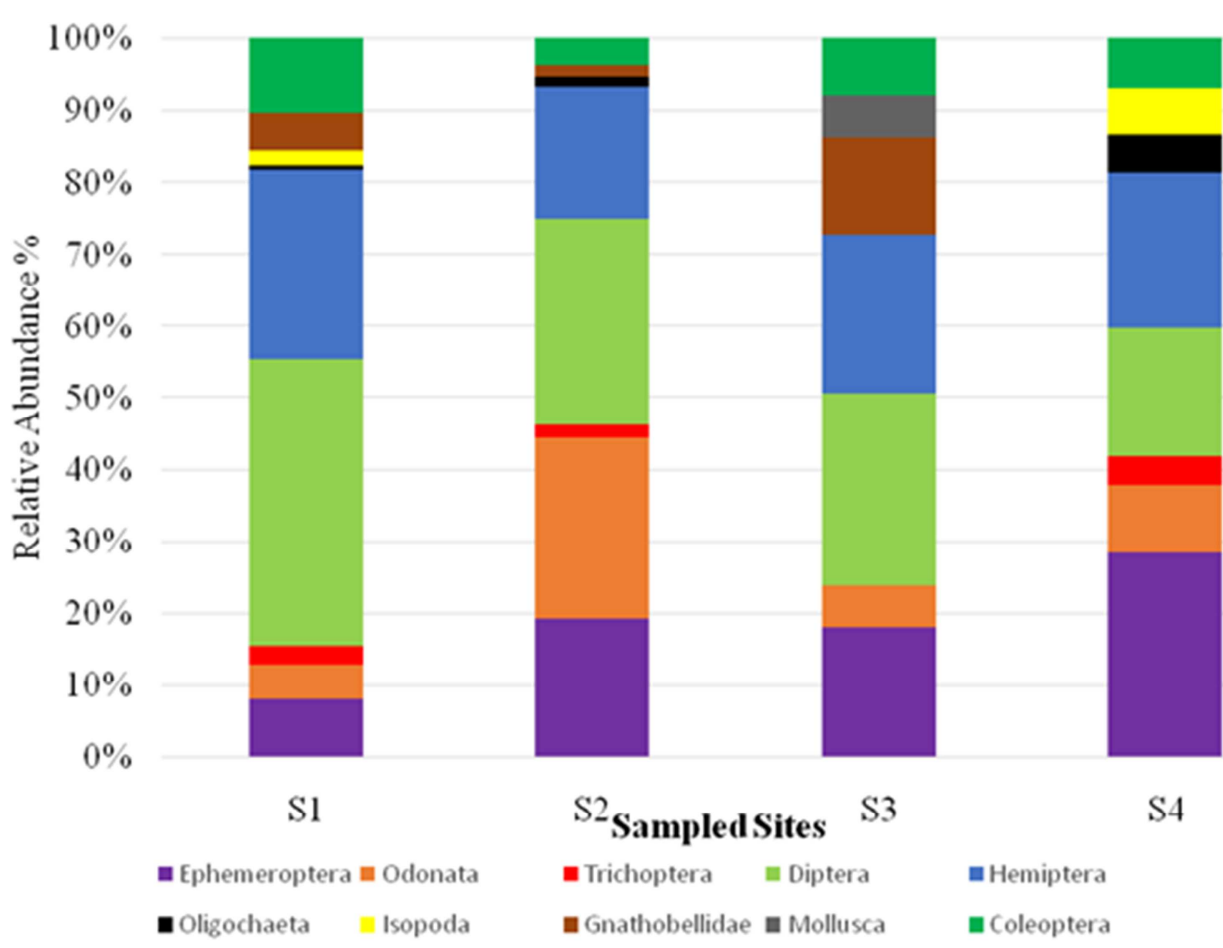

Figure 7. The relative abundance of benthic macroinvertebrates orders at the sampling sites.

\section{Discussion}

\section{Water Quality Parameters}

The difference in physio-chemical parameters among the stations can be attributed to proximity of the flower farm and the land use practices along the wetland. S2 for instance, had the lowest $\mathrm{pH}$ value and this was a result of high temperatures due to reduced vegetation cover. According to Bowman et al., (2006), high temperatures usually increases the rate of evaporation inducing acidification of aquatic ecosystems thus lowers the ph. S3 had the highest $\mathrm{pH}$ value and could be as a result of the chemicals used in the flower farm which are rich in basic compounds, when dissolved in water may cause raise in $\mathrm{pH}$ levels. S1 had the lowest temperature recorded due to the high vegetation cover in the area. Vegetation cover reduces light penetration reaching the water thus reducing temperature fluctuations. Little vegetation cover and low water volume made S2 to have the highest temperature recorded. The little vegetation cover in $\mathrm{S} 3$ was as a result of crop growing near the flower farm. DO values were low in S3. This can be related to higher temperature caused by reduced vegetation cover and human activities like car washing due to its close proximity to road and effluents from the flower farm since the station is near to the farm. TSS values are affected by different factors including, increase in temperature water flow and weather, point source pollution like in this case, from the flower farm and land use (Bailey et al. 1994). High TDS in S3 was as a result of the high dissolved chemical components in the water from the flower farm effluent. These were from the fertilizers and herbicides used in the flower farming among other crops grown at the Equator flower farm. High temperature, low DO and BOD at S3 highly influenced the composition and abundance of benthic organisms, with members of oligocheata and isopoda being total absent. Total nitrogen was the highest in S 3 because of the chemicals that are used at the Equator flower farm ie. fertilizers and herbicides contain nitrogen compounds. In $\mathrm{S} 1$ it was also a bit high because of the 
agricultural practice ie. the growing of crops such as kales.

Ammonia on the other side was highest in S3 and this is usually the inverse of oxygen whereby when the level of oxygen is low, the level of ammonia is high. This was because of the wastes from the aquatic animals and due to lower DO, ammonia could not be easily removed. Phosphorus level was the highest in S2 and lowest in S1 because of the car wash just few metres from the sampling site 2 (S2). From researches such as (Robert and Rankin, 1998), it has been seen that animal grazing, car washing and crop cultivation have an effect on the nutrient level. Lower values in Shannon Weiner show that the place is polluted. Therefore, site 3 showed lower values than other sites meaning the place was more polluted. The increased diversity in sampling station 1 was due to fairly disturbance of the wetland by human activities compared to the other stations favouring the growth of the macrophytes allowing different organisms to dwell there. Dipterans were the most abundant while mollusca was the least abundant. This is because most of them could tolerate in all the conditions despite some being in poor state like site 3 . The benthic community was dominated with diptera and hemiptera which had larger number of macro-invertebrates and were found at all sites. The high numbers of these taxa can also be attributed to organic pollution as a result of enrichment and sedimentation caused by agricultural activities and excretion by livestock in the wetland (Buss et al. 2002). High nutrient enrichment and sedimentation have been shown to favour some Chironomidae, Trichoptera, Mollusca and Oligochaeta (Quinn et al. 1997).

Families such as Baetidae, Chironomidae, Gerridae and Zygoptera were tolerant because they were found in all the sampling sites. Syrphidae, Mollusca and Nepidae are considered more tolerant due to the fact that station 3 had very low DO and BOD. Lestidae was found in station 1 and 4 as they are less tolerant as compared to other organisms (Mandaville, 2002). An increase in the fraction of Odonata and disappearance of members of order Trichoptera in site 3 also indicated a decline in water quality, since. Therefore, this study revealed that macro-invertebrate communities responded to changes in water quality along the river. Despite little apparent change in taxa richness observed at the different stations, there were marked shifts in dominance and composition of the macro-invertebrates. The study Macroinvertebrate communities in the wetland are good candidates for assessing water quality and general ecosystem integrity. With intensification of agricultural activities in the watershed there is a need to consider macro invertebrate assemblages in future water quality monitoring programs in the river.

\section{Acknowledgement}

The authors wish to thank Fisheries department university of Eldoret for providing us with facilities for laboratory work. Dr. Masese for insightful contribution and reviews. Mr. Odhacha and Mr. Lubanga helping us in macro-invertebrates identification. Mukhwana who conceived the study. The authors declare no conflicting financial interest.

\section{References}

[1] APHA (American Public Health Association), 2005. Standard methods for the examination of water and wastewater, 20th edn. Washington, D. C. American Public Health Association, America Water Works Association, and Water Pollution Control Federation. https://www.apha.org/. (accessed on October 2014).

[2] Bailey R. G., Busulwa H. \& Williams A. 1994. The aquatic habitats and Fisheries of the Rwenzori Mountains Rivers, Uganda. Darwin Initiative Report no. 14. Kings College London, London, 106. (http://link.springer.com/book/10.1007/978-1-4020-9726-3).

[3] Bowman M. T., Keith M. S., Reid R. A. \& Scott L. D. 2006. Temporal response of stream benthic macro-invertebrates' communities to the synergistic effects of anthropogenic acidification and natural drought events. Freshwater Biol, 51: 768-782, doi: 10.1111/j.13652427.2006.01516.x.

[4] Clenaghan, C., Giller P. S., O'Halloran J. \& Hernan R. 1998. Stream macroinvertebrate communities in a conifer-afforested catchment in Ireland: Relationships to physico- chemical and biotic factors. - Journal of Fish Biology, 14, 165-75. doi: 10.1046/j.1365- 2427.1998.00330.x.

[5] GEF (Global Environmental Facility) (2004). Western Kenyaintegrated ecosystem project; Executive Summary. Available athttp://www.gefweb.org/Documents/CouncilDocuments/-C23/. (Accessed on September 2016).

[6] Gerber, A. and Gabriel, M. J. M. 2002. Aquatic Invertebrates of South African Rivers Field Guide. Institute of water quality studies, department of water affairs and forestry. First edition. http://extension.usu.edu/water quality (accessed in September 2015).

[7] Gill K. 2008. Identification Guide to Fresh Water Macro invertebrates Stroud Water Research Centre. Hammer Ø, Harper DAT, Ryan PD. 2001. PAST: Paleontological Statistics Software Package for Education and Data Analysis. Palaeontologia Electronica 4 (1). Stroud Water Research Centre. Pennsylvania 19311. 184

[8] Jaetzold, Ralph, and Helmut Schmidt. 1983. Farm management handbook of Kenya. 4 vols. Nairobi: Kenya $\begin{array}{llll}\text { Ministry of } & \text { Agriculture. }\end{array}$ http://www.abebooks.com/?cm_sp=TopNav-_-Results-_Logo. (accessed on December 187 2014).

[9] Mandaville S. M. 2002. Benthic Macroinvertebrates in Freshwaters-Taxa Tolerance Values, Metrics, and Protocols. (Project H-1) Soil and Water Conservation Society of Metro Halifax press. 54 pp.

[10] Masese F. O., Muchiri M. \& Raburu P. O. 2009. Macroinvertebrate assemblages as biological indicators of water quality in the Moiben River, Kenya. African journal of aquatic sciences. 193 2009, 34 (1): (15-26) doi: 10.2989/AJAS.2009.34.1.2.727

[11] Mitsch M. J. \& Gosselink J. G. 2007. Wetlands 4th Edition. (Hardcover) (2007). 
[12] Robert J. Miltner and Edward T. Rankin. 1998. Blackwell Science Ltd, Freshwater Biology, 40, 145-158.

[13] Postel S. 1992. Last Oasis: Facing Water Scarcity. Worldwatch environmental series. London: Edward Arnorld. ISBN: 0-393-31744-7. 240 pp.

[14] Quinn J. M., Cooper A. B., Davies-Colley R. J., Rutherford J. C., Williamson R. B. 1997. Land-use effects on habitat, water quality, periphyton, and benthic macroinvertebrates in Waikato, New Zealand, hill-country streams. New Zealand Journal of Marine and Freshwater Research (special İssue): 32: 579-597.
[15] Wetzel G. R. 1975. Limnology 2nd Edition. W. B. Saunders Co., Philadelphia. 743 pp.

[16] Winterbourn, and M. J. Collier, K. J (eds). 2000. New Zealand stream invertebrates: ecology and implications for management. New Zealand Limnological Society (NZFSS), Christchurch. P. 455. 